\title{
COMMENTS ON PARFIT
}

I will begin by saying that I am persuaded by most of Derek's claims and arguments. That may tend to make for rather uninteresting commentary, but I shall try to find something to say. I shall offer only one criticism of the main part of Derek's paper, and then I shall discuss at somewhat greater length the questions he raises in the last section of his paper.

In the main body of the paper, Derek attempts to prove that if we accept what he calls the Complex View of personal identity, then we must abandon what he calls the Equal Concern Claim of Classical Prudence. The basic argument is simple. On the Complex View, personal identity is a matter of degree. But it is not irrational to think that a fact which is a matter of degree is of lesser importance when it holds to a lesser degree. Therefore, it is not irrational to think that one's identity with oneself in the distant future may be of lesser importance than one's identity with oneself in the near future. It follows that it is not irrational to give greater weight to one's interests in the near future. Classical Prudence is not a requirement of rationality.

My only criticism of this argument may seem, and indeed may be, niggling. Derek relies on the claim that on the Complex View identity is a matter of degree. But is it, necessarily? The Complex View is defined primarily by contrast to the Simple View. Derek also says that on the Complex View, "the fact of personal identity over time just consists in the holding of certain other facts," such as various kinds of psychological continuity. Now suppose someone says, "Personal identity consists simply in continuity of physical and psychological development - nothing else. That is, we look at one person-at-a-time and another person-at-a-different-time; if the person-at-the-later-time developed by a continuous, non-disrupted process from the person-at-the-earliertime, then the two are in fact the same person." I shall call this view the Developmental View. It seems to me that the Developmental View is a Complex View, in Derek's terms, but a Complex View on which personal identity is not a matter of degree. 
Derek overlooks the Developmental View because he tends to equivocate, both when he uses the word "continuity" and when he uses the word "connected," between two ideas that naturally go together. One of these is roughly the idea of a development from one state to another without "jumps"; and the other is the idea of resemblance of the end points of the development. Resemblance of the end points, which Derek concentrates on, is certainly a matter of degree. But one could say that all that matters to personal identity is development without jumps. Then one has the Developmental View, and a Complex View on which personal identity is an all-or-nothing matter.

Derek might protest that even continuity of development is a matter of degree. What disrupts continuity of development? Well, things like brain-washing, or extremely intrusive electric shock therapy. These constitute "jumps" in development. But then, Derek might observe, brain-washing and electric shock therapy come in degrees. If identity depends on the absence of jumps, and if the things which can constitute jumps come in degrees, then identity will turn out to be a matter of degree after all.

This is a good point, but not good enough. I concede that it makes personal identity a matter of degree in some cases, for example, in the cases of people subjected to brainwashing of "borderline" intensity or disruptiveness. But the vast majority of people are not subjected to brainwashing, or electric shock therapy, or anything else that a proponent of the Developmental View would have to recognize as potentially disrupting continuity of development, in any degree at all. With respect to the vast majority of people, on the Developmental View, no question of degree ever arises, and Derek has no argument against the Equal Concern Claim. (I simply note, without explaining, that what I am saying here is different, despite some superficial similarity, from Derek's point that even on his view the resemblances of people to themselves over all actual lives are probably great enough so that it would never be irrational to care equally about all parts of one's future.)

Derek might now complain that the Developmental View is extremely implausible. If we abandon the Simple View and look for the fact of personal identity among "natural" facts, then surely resemblance of the end points of development must count for something. On the issue of plausibility, I would agree. The Developmental 
View is implausible, and I suspect that anyone who held it would be engaged in rationalization, trying to hold the Simple View in effect without having to defend it. Still, the existence of the Developmental View reveals a gap in Derek's logical argument.

Everything else I shall have to say is about the last section of Derek's paper. If Classical Prudence is defeated - and despite my carping I agree with Derek that it is - we are left with the issue of how to justify a kind of criticism we are strongly disposed to make, namely criticism of an agent for showing insufficient concern for his own future interests. Derek suggests that if we cannot base our criticism on an appeal to rationality, then morality must step in to fill the gap. He makes no attempt to conceal the fact that this suggestion is in one respect highly counterintuitive. We are accustomed to think of morality as imposing restrictions on an agent for the protection of others. To the extent that we have traditionally recognized selfregarding moral duties, they have been duties of perfection - duties to cultivate one's talents or to preserve one's purity, to use Derek's examples. We have not generally thought of morality as the source of a duty to look out for one's own general future happiness. But that is what Derek proposes.

We could avoid this counter-intuitive aspect of Derek's appeal to morality if we were willing to say that the agent's future selves are "different persons" from the present agent. Then the appeal to morality would be on behalf of "others." Derek does not take this line. Indeed, there is a passage in his paper where it seems he is taking particular care not to be trapped into it. After his discussion of the propositions that not all relatives are equally close and that not all pains are equally painful, there is a point at which it would be very natural for him to say that not all of my interests are equally mine (and specifically that my future interests are less mine than my present interests). Derek refuses to say that my future interests are less mine. One reason, I suspect, is that if he said my future interests were not in the fullest sense mine, it would invite the question of whose exactly they are. They are ordinary, full-fledged, human interests. They must be fully somebody's. If not mine, then whose? To which the obvious answer would be that the interests in question belong fully to my "future self" (or to one of my future selves), regarded as somebody different from me.

Unlike Derek, I am inclined to take the view that my future selves 
are different persons from my present self. Admittedly, this view has its own difficulties and its own counter-intuitive aspect. In ordinary discourse, we speak as if one physical body is occupied by one person throughout that body's physical life. We speak as if we have no doubt that Donald Regan fifty years hence, if I live so long, will still be $m e$. We certainly do not believe in general that a change in something always constitutes a change in identity. We do not believe that about ships or nations. Furthermore, if we take seriously the idea that the agent in the future may be a different person from the person he is at present, then we encounter severe problems about deciding just exactly when he becomes another person. How do we separate the time-extended agent into the different persons that he is over his physical life?

Both Derek's suggestion and mine, then, are problematic. This is not the place for a full-scale attempt to arbitrate between them. It seems to me that Derek resists tampering with the normal extension of "self" and "other," but that in consequence he is driven to deprive the distinction between self and other of a good deal of its normal moral force. In the long run, whether we prefer my view or Derek's may depend on the extent to which our interest in personal identity is motivated primarily by moral, as opposed to metaphysical, concerns. In the short run, so long as we agree on cases, as Derek and I mostly do, it may not matter too much what we say. (In the remainder of these comments, I shall presuppose Derek's view that myself in the future is still "me.")

All of this raises the question whether there is a way to analyze the case of the agent who slights his own future interests which ought to be preferred to both Derek's view and mine. Someone might say: "In the case of an agent who slights his own future interests, there is no basis for moral criticism because he hurts no one else. There is no basis for an accusation of irrationality, as Derek has shown. Therefore, there is no basis for any criticism at all. If we have an impulse to criticize, we should rather look to ourselves and suppress the impulse." (This argument depends on an implicit premise that if there is no basis for saying the agent is either immoral or irrational then there is no basis for criticism. This implicit premise is plainly Derek's, to the extent he assumes morality must fill the space prudence vacates.) The claim that there is no basis for criticism could be made somewhat plausible, but $I$ think it is ultimately indefensible. I shall not here attempt either to build it up or to tear it down. I only note that the 
question presently at issue is not whether we should coerce people to look out for their own future interests. It is only the question whether there is a basis for criticism when people do not. The common view, and Derek's view and mine, is that some sort of criticism is surely appropriate.

Consider another possible reaction to Derek's argument: "Derek has shown that if we accept the Complex View of personal identity, then the person who slights his own future interests is not irrational. $\mathrm{He}$ is also not immoral, since no one else is harmed. Therefore his behavior is unexceptionable. But that is absurd. We know he is behaving badly somehow. Obviously what Derek has given us is a reductio ad absurdum of the Complex View." This reaction may seem out of bounds. Derek does not purport to argue for the Complex View in his paper. He takes it for granted, assuming that it can be justified by arguments he does not here expound. However, the reaction I have described is not entirely inappropriate. It reminds us that we should not attempt to choose between the Simple View and the Complex View of personal identity on metaphysical grounds alone. One factor in the choice is the alternatives the two views allow us for accounting for our "practical" (moral and prudential) intuitions. If the Complex View creates difficulties on this score which the Simple View avoids, that counts against the Complex View (without necessarily being decisive).

I just said, "If the Complex View creates difficulties on this score which the Simple View avoids...." That raises a question about the Simple View which I hope will justify one paragraph of out-and-out digression. Derek assumes, as most people do, that the Simple View fits easily with Classical Prudence and the Equal Concern Claim; but there is a difficulty even here. The Simple View naturally leads us to think of the self as an entity somehow outside time. It is because the self is essentially timeless that it should be neutral among its temporally-distinct interests. Consider this however: If the self is essentially timeless, and if it is that timeless self that makes the choices that are manifested in the temporal world, how could an agent possibly fail to be temporally neutral? We assume that people frequently fail to be temporally neutral, that people have an inclination to over-value their present interests. But the timeless self of the Simple View could have no motive for such a time-preference. If we truly believed in the Simple View, then should we not assume that in any case where an agent appears to us to be temporally biased, the 
reason is that we have misperceived the agent's true interests? (Of course, even the timeless self might exhibit an apparent time-preference because of factual mistake, or uncertainty about the future, or the like. I am concerned with apparent time-preference which remains after such factors have been accounted for.) The tension I am pointing out is not really between the Simple View and Classical Prudence; it is between the Simple View and our impulse to criticize some behavior as classically imprudent. If we believe not only in the rightness of Classical Prudence, but also in the rightness of our criticisms on the ground of imprudence, then there is some reason to doubt that we can hold the Simple View after all. (I say "some reason" because this paragraph obviously raises issues much too complex for full discussion here.)

Let me now say just a few words about Derek's final question: If the agent who slights his own future interests is thought to behave immorally instead of imprudently or irrationally, does that strengthen or weaken the case for paternalistic intervention? Intuitively, it seems as if it might strengthen it, and I think we can produce a sort of an argument to that effect. We have inclinations both to coerce shortsighted agents to behave prudently and to coerce selfish agents to behave morally. But prudence and morality may conflict. In cases of conflict, if we engage in coercion at all, we will compel the behavior which is moral but imprudent. We are not at all inclined to compel the behavior which is prudent but immoral. That suggests that morality is in some relevant sense stronger than prudence, so that if we shift from prudence to morality as the basis for protecting the agent's own future interests, we are now appealing to a stronger basis for intervention.

I am not sure the argument just given is very helpful. The problem is that it assumes morality in its new role of protecting the agent's future interests has the same force as morality in its old role of protecting other agents. It is not at all clear, however, that morality in its new role does have the same force. If we pose the question as one of institutional design, then there are good reasons for treating morality as not having the same force in its new role as in its old. One of the standard objections to paternalism based on prudence and rationality is that the paternalist is likely to make mistakes. The agent is likely to know best about what will promote his own future interests. That remains true whatever the ultimate normative basis of our impulse to intervene. Similarly, the shift from prudence to moral- 
ity does not affect the fact that an agent seems more likely to look out for his own future interests than to look out for the interests of others.

I have suggested (and criticized) an argument that the shift from prudence to morality strengthens the case for paternalistic intervention. Let me now suggest an argument for the opposite conclusion. There can be no objection at all, someone might say, to interfering with a choice which is irrational. A choice which is irrational simply cannot be the fully-deliberated choice of a fullycompetent agent. But it is only the fully-deliberated choices of fully-competent agents that have an intrinsic moral value such that we should refuse to interfere with them. An immoral choice, in contrast, can be the fully-deliberated choice of a fully-competent agent. It is unfortunate, but it is the case, that some agents just choose, in the fullest possible sense of "choose," to act immorally. Still, these are responsible choices. If the agent harms no one else by his immoral choice (and when he harms only himself-in-the-future he harms no one else, in Derek's view), we should not interfere. In sum, if Derek has shown that the agent who slights his own future interests behaves immorally but not irrationally, then he has shown that the intervention which we thought was justified in fact is not.

This argument, as it stands, is hardly more satisfying than my first argument. It is suggestive, but every premise is highly controversial, and some of the premises seem to beg the very question about the strength of the justification for paternalism we are trying to answer.

The upshot is that I do not know how to answer Derek's final question on principle. Perhaps we must simply go forward thinking about the cases, designing institutions, and generally trying to see how strong the reasons for paternalism (and against it) are, without worrying too much at this stage about what difference it makes how we characterize those reasons. Lest I be misunderstood, I should add that I think the general tendency of Derek's argument is clearly to strengthen the case for paternalism. I think the Complex View of personal identity fits better than the Simple View with the idea that we should sometimes intervene to protect an agent against himself. It's just that for me Derek's final question is not the natural point of entry into an explanation of why that is so.

University of Michigan 